\title{
A FACTICIDADE DO PARA-SI, O OUTRO E AS TRÊS DIMENSÕES ONTOLÓGICAS DO CORPO EM O SER E O NADA, DE SARTRE
}

\author{
Vinícius Loureiro Renaud \\ Mestrando em Filosofia na Universidade Federal Fluminense - UFF
}

\section{RESUMO}

Se na parte inicial de $O$ ser e o nada, na tentativa de desenvolver sua ontologia fenomenológica, o problema da síntese irrealizável entre em-si e para-si parece sintetizar as questões centrais da filosofia sartriana, ao final da segunda parte, especificamente no terceiro capítulo, intitulado "A transcendência", Sartre revela um outro modo de existência tão fundamental quanto o ser-Para-si: o ser-Para-outro. A realidade humana é efetuada e esclarecida pela experiência do olhar, mediante uma fenomenologia do corpo. Nesse sentido, o tema do corpo na ontologia fenomenológica sartriana é vital para a compreensão tanto da relação com o outro como da "facticidade" do Para-si, sendo a facticidade conceito imprescindível para se entender o significado da liberdade na obra do filósofo francês. Assim, vamos guiar-nos pela descrição que Sartre faz das três dimensões ontológicas do corpo.

Palavras-chave: Jean-Paul Sartre; Outro; Corpo.

\begin{abstract}
If inicially Being and Nothingness, by trying to develop its own phenomenological ontology, the problem with the unrealizable synthesis between In-Itself and For-Itself seems to take over and manage the matters that dwell the objectives of Sartre's philosophy, by the end of the second part, specifically in the third chapter, entitled "Transcendence", Sartre reveals another way of existence as fundamental as Being-ForItself: Being-For-Others. Human reality is accomplished and clearified by sight experience, through a phenomenology of the body. In this case, the topic of the body in Sartre's phenomenological ontology is vital for the comprehension of the relation with another as much as the "facticity" of For-Itself, being facticity an essential concept to understand the meaning of liberty in the work of the french philosopher. This way, we will guide ourselves by the description that Sartre makes regarding the ontological three dimensions of the body.
\end{abstract}

Keywords: Jean-Paul Sartre; Other; Body.

Se na parte inicial de $O$ ser e o nada, na tentativa de desenvolver sua ontologia fenomenológica, o problema da síntese irrealizável entre Em-si e Para-si parece ocupar e dar conta das questões centrais aos objetivos da filosofia sartriana, ao final da segunda parte, especificamente no terceiro capítulo, intitulado "A transcendência", Sartre, ao abordar os modos de relação e a possibilidade de conhecimento na relação Para-si/Em-si, revela um outro modo de existência tão fundamental quanto o ser-Para-si: o ser-Para-outro. É interessante salientar a importância que o corpo assume na relação entre duas consciências: 
O corpo - nosso corpo - tem por caráter particular ser essencialmente o conhecido pelo outro: o que conheço é o corpo dos outros, e o essencial do que sei de meu corpo decorre da maneira como os outros o veem. Assim, a natureza do meu corpo me remete à existência do outro e a meu ser-Para-outro. Descubro, com ele, para a realidade humana, outro modo de existência tão fundamental quanto o ser-Para-si, que denominaremos ser-Para-outro. Se almejo descrever de forma exaustiva a relação do homem com o ser, é necessário agora abordar o estudo desta nova estrutura de meu ser: o Para-outro. Pois a realidade humana, em um único e mesmo surgimento, deve ser em meu ser Para-si-Para-outro (Sartre, 1997, p. 286).

No fundo, a realidade humana, o Para-si, é um ser-Para-si-Para-outro, em que o outro é condição necessária para a constituição do Para-si como tal, em uma relação que é efetuada, vivenciada e esclarecida pela experiência do olhar ${ }^{1}$ - a dupla relação olhar/ser olhado é o elemento principal de decifração desta nova perspectiva existencial. Segundo Moravia (1985, p. 59): “O encontro com o Outro determina a inquietante desdoberta da 'falta' e da heteronomia do Eu. O sujeito dá-se conta de ter sido visto e descoberto na sua própria objetividade (que para ele é inatingível) através de algo que está fora de si”. Por meio do outro, o Para-si é capturado como Em-si; sua consciência, atingida pela experiência do olhar, depara-se com sua transformação em objeto. O outro remete o Para-si a fenômenos situados fora do conjunto de referenciais, do mundo, desse próprio Para-si: “A percepção do objeto-outro remete a um sistema coerente de representações, e esse sistema não é o meu [...] se refere por princípio a fenômenos situados fora de toda experiência possível para mim” (Sartre, 1997, p. 296). Ser-visto, para o Para-si, faz com que este vivencie a constituição de um ser sem defesa perante uma (outra) liberdade que não a dele. Nesse sentido, o Para-si estaria sempre em perigo em relação ao outro, sendo esse "perigo" não um acidente, mas sim a estrutura permanente do ser-Para-outro (id., ib., 344) - o Para-si já não seria mais “dono da situação". Para Sartre, a relação entre o Para-si e o outro, ou seja, a revelação do Para-si como Para-si-Para-outro, se dá por intermédio do corpo, que é o que

\footnotetext{
${ }^{1}$ Uma exposição completa do problema do "olhar" talvez ficasse mais claro com o exemplo que Sartre utiliza acerca da experiência da "vergonha". No entanto, tal descrição fugiria um pouco do intento do objetivo aqui, mas a síntese realizada por Donizetti da Silva (2010, p. 45) parece dar conta do que estava em questão no exemplo citado: "A liberdade, antes infinita, encontra-se ameaçada ante o olhar estrangeiro; minhas possibilidades, antes ilimitadas, parecem se congelar [...] É pelo outro que o para-si descobre uma parcela até então desconhecida de seu ser, que se reconhece como em-si, como natureza. Existencialmente, ante o olhar do outro, o homem experimenta a vergonha e o medo; sente-se ameaçado, coagido, restringido a não mais que um objeto [...] É pelo ser-para-outro que o para-si descobre uma parcela de seu ser (liberdade) que está alienada à mercê do outro. Ainda que isso não modifique a essência da realidade humana, pois ser para-si é ser liberdade, o outro coloca essa liberdade em risco; o outro coloca o que eи sou em perigo".
} 
propicia uma dupla relação sujeito-objeto - o corpo é o que é conhecido pelo outro, assim como o que se pode conhecer do outro é seu corpo; além disso, o que se pode saber sobre seu próprio corpo é decorrente do modo como é visto pelo outro. Como explicita Jolivet (1968, p. 101):

O problema do outro, em Sartre, articula-se com o problema do corpo. Este, de fato, como o mundo onde está, pertence ao conhecido. Logo, impossível atribuir ao corpo o conhecimento, porque o supõe e porque meu corpo tem por característica essencial ser o conhecido-por-outro, de forma que aquilo que apreendo de meu corpo deriva do modo como é visto por outro. Assim sendo, o meu corpo me remete ao outro e ao ser que sou para o outro, fazendo-me descobrir uma nova maneira de existir, que denominaremos o ser-para-outro e que é tão fundamental quanto o ser-para-si, donde se conclui que a realidade humana aparece sempre, a um só tempo, como para-si-para-outro.

O tema do corpo na ontologia fenomenológica sartriana é vital para a compreensão tanto da relação com o outro como da "facticidade" do Para-si (e o entendimento do homem como ser em situação), sendo a facticidade conceito imprescindível para se entender o significado da liberdade na obra do filósofo francês, uma vez que da relação liberdade/facticidade emergem questões relacionadas à responsabilidade e à ética. Nesse sentido, o guia para este texto é a descrição que Sartre faz do "corpo" no livro $O$ ser e o nada, apresentando aquilo que o autor classificou como "as três dimensões ontológicas do corpo", uma discussão presente no segundo capítulo da terceira parte da obra apontada.

A primeira dimensão ontológica do corpo é a revelação do corpo como ser-Para-si. O Para-si é relação com o mundo; não há, de um lado, o Para-si e, de outro, o mundo, só há mundo pela e para a realidade humana, que, transcendendo rumo às suas possibilidades, descobre os "istos" como coisas-utensílios. O Para-si é-no-mundo. É de acordo com o comprometimento do Para-si no mundo que as coisas vêm à tona: “O homem e o mundo são seres relativos, e o princípio de seu ser é a relação. Segue-se que a relação primeira vai da realidade humana ao mundo. Surgir, para mim, é estender minhas distâncias às coisas e, por causa disso, fazer com que haja coisas" (Sartre, 1997, p. 390-391). Por isso, todo ponto de vista do conhecimento é comprometido, o que para Sartre "equivale a dizer que conhecimento e ação não passam de duas faces abstratas de uma relação original e concreta" (id., ib.).

O conhecimento que se formula dos objetos, das coisas-utensílios, só pode se dar a partir do comprometimento pelo fato de o homem ser um determinado ponto de vista: "Ser, para a 
realidade humana, é ser-ẩ’ (id., ib.). O que quer dizer estar aí, sentado na cadeira, aí, junto a esta mesa, aí, no alto desta montanha, com tais dimensões, tal direção, função e intenção. Compreender a realidade humana como "ser-aí" implica a perspectiva de os objetos estarem sempre em relação ao Para-si segundo uma determinada orientação. E ocupar uma distância e um posicionamento específicos às coisas do mundo, para o Para-si, segundo Sartre, "é uma necessidade ontológica" (Sartre, 1997, p. 391). Essa necessidade ontológica é mais bem compreendida pela apresentação de duas contingências, por meio das quais é possível entender o conceito de "facticidade do Para-si":

Por um lado, com efeito, se é necessário que eu seja em forma de ser-aí, é totalmente contingente que assim seja, porque não sou fundamento de meu ser; por outro lado, se é necessário que eu seja comprometido neste ou naquele ponto de vista, é contingente o fato de que só posso sê-lo em um desses pontos de vista, com exclusão de todos os outros. É esta dupla contingência, encerrando uma necessidade, que denominamos facticidade do Para-si [...] O Em-si, nadificado e aniquilado no acontecimento absoluto que é a aparição do fundamento ou surgimento do Para-si, permanece no âmago do Para-si como sua contingência original. Assim, o Para-si é sustentado por perpétua contingência que ele recupera por conta própria e assimila sem poder suprimi-la jamais. Em parte alguma o Para-si a encontra em si mesmo, em parte alguma pode captá-la e conhecê-la, sequer pelo cogito reflexivo, porque a transcende sempre rumo às suas próprias possibilidades e só encontra em si mesmo o nada que tem-de-ser. E, contudo, essa contingência não cessa de impregná-lo, fazendo com que eu me apreenda ao mesmo tempo como totalmente responsável pelo meu ser e como totalmente injustificável. Mas esta injustificabilidade (injustifiabilité) tem sua imagem a mim devolvida pelo mundo em forma de unidade sintética de suas relações unívocas comigo" (id., ib., p. 391-392).

O modo como o Para-si ocupa essas relações e distâncias com os objetos do mundo, a contingência que habita essa relação, o que dá ordem aos modos de aparecimento dessa relação, é o corpo. A existência do Para-si como corpo é o que possibilita "estar posicionado em relação a", "tomar distância específica em relação a", comprometer-se e relacionar-se com quaisquer objetos disponíveis à sua realidade, seu mundo, seu entorno: "Nesse sentido, poder-se-ia definir o corpo como a forma contingente que a necessidade de minha contingência assume. Nada mais é do que o Para-si [...] o corpo não se distingue da situação do Para-si, uma vez que, para o Para-si, existir e situar-se constituem a mesma coisa" (id., ib., p. 392). Por outro lado, há uma identificação entre corpo e mundo, tendo em vista que este é a situação total do Para-si e medida de sua existência. 
Ambos se revelam como aquilo que o Para-si terá de transcender rumo a seu projeto de ser; ${ }^{2}$ o corpo, assim como o mundo, não pode ser conhecido pelo Para-si, e sim vivido ao modo daquilo que é transcendido. Segundo Sartre (id., ib., p. 392-393), o corpo

só existe na medida em que dele escapo nadificando-me; é aquilo que nadifico. É o Em-si transcendido pelo Para-si nadificador e que recaptura o Para-si nesse transcender mesmo. É o fato de que sou minha própria motivação sem ser meu próprio fundamento; o fato de que nada sou sem o ter-de-ser o que sou, e que, todavia, na medida em que tenho-de-ser o que sou, o sou sem ter-de-sê-lo. Em certo sentido, portanto, o corpo é uma característica necessária do Para-si [...] advém necessariamente da natureza do Para-si o fato de que ele seja corpo, isto é, que seu escapar nadificador ao ser seja feito em forma de comprometimento no mundo. Todavia, em outro sentido, o corpo manifesta bem minha contingência, inclusive não é senão esta contingência [...] o corpo representa a individualização de meu comprometimento no mundo.

O corpo indica o modo de entrada, o vir ao mundo, assim como também a existência de um mundo, no sentido de que o corpo está por toda parte no mundo. Ao remeter ao modo específico com o qual um determinado Para-si estará em relação e estará no mundo, revela-se como a contingência da realidade humana é explicitada mediante uma individualização que se dá por ser corpo, pelo fato de consciência e corpo não estarem dissociados. O corpo, diz Sartre, é "centro de referência total indicado pelas coisas", além de ser "o instrumento e a meta de nossas ações” (id., ib., p. 404), e essas afirmações ganham sentido somente se se compreender que

todo meio é, ao mesmo tempo, favorável e adverso, mas nos limites do projeto fundamental realizado pelo surgimento do Para-si no mundo. Assim, meu corpo é indicado originariamente pelos complexos-utensílios e secundariamente pelos aparatos destruidores. Eu vivo meu corpo em perigo, tanto face aos aparatos destruidores quanto face aos instrumentos dóceis. Meu corpo está por toda parte (id., ib., p. 410).

Nesse aspecto, o corpo é a relação original do Para-si com o mundo, ele é revelado mediante o mundo, em que as coisas-utensílios indicam o corpo ao Para-si. Somente "em um mundo" pode existir um corpo, e, se por um lado, este é o que o Para-si é imediatamente, por

\footnotetext{
${ }^{2}$ Sobre o conceito de "projeto", diz Sartre (2005, p. 170-171): "Nossa existência é "tentativa exasperada de consumar o ser'. O horror de nossa condição é tal que na maior parte do tempo renunciamos, tentamos nos evadir no projeto, quer dizer, nessas mil ocupaçõezinhas que têm um sentido apenas restrito e que mascaram a contradição com os fins que elas projetam diante de si [...] $\mathrm{O}$ projeto, de fato, diz respeito à preocupação de ordenar a vida. $\mathrm{O}$ homem que
} 
outro, o Para-si está separado de seu corpo "pela espessura infinita do mundo; o corpo é-me dado por um refluxo do mundo rumo à minha facticidade, e a condição desse reflexo perpétuo é um perpétuo transcender" (id., ib., p. 411). O corpo manifesta o modo individual e contingencial no qual um Para-si se relaciona com os objetos contidos em seu mundo de forma originária. Sartre afirma que o corpo é o passado, na forma daquilo que é o transcendido, um centro de referência às sensações-ações (que não são separáveis, já que o sentir não se dá puramente, sem receber uma significação que é, ao mesmo tempo, um agir sobre uma situação) rumo a uma nova combinação, uma transfiguração, das coisas-utensílios de acordo com um outro projeto do Para-si:

Em cada projeto do Para-si, em cada percepção, o corpo está aí, é o Passado imediato enquanto ainda aflora no Presente que lhe foge. Significa que é, ao mesmo tempo, ponto de vista e ponto de partida: ponto de vista, ponto de partida que sou e, ao mesmo tempo, transcendo rumo ao que tenho-de-ser. Mas esse ponto de vista perpetuamente transcendido e que perpetuamente renasce no âmago do transcender, esse ponto de partida que não cesso de transpor e sou eu mesmo ficando para trás de mim, é a necessidade de minha contingência. É duplamente necessário. Primeiro, porque é a recuperação contínua do Para-si pelo Em-si e o fato ontológico que o Para-si só pode ser enquanto ser que não é seu próprio fundamento: ter um corpo é ser fundamento de seu próprio nada, mas não ser fundamento de seu ser; sou meu corpo na medida em que sou; não sou meu corpo na medida em que não sou o que sou; dele escapo por minha nadificação. Mas nem por isso dele faço um objeto, porque aquilo de que perpetuamente escapo é aquilo que sou. E o corpo, além disso, é necessário como obstáculo a ser transcendido para ser no mundo, ou seja, obstáculo que sou para mim mesmo. Nesse sentido, não difere da ordem absoluta do mundo, esta ordem que faço advir ao ser transcendendo-o rumo a um ser-por-vir, rumo ao ser-para-além-do-ser (Sartre, 1997, p. 412).

O corpo é o ponto de partida da transcendência característica da consciência como Para-si como ser em um mundo, em que o corpo indica e localiza a radicalidade da contingência como indissociável da realidade humana - o corpo "é uma condição necessária de minha ação" (id., ib., p. 413). O Para-si é corpo, na medida em que não poderia ser nada além de corpo, ao mesmo tempo que ser esse corpo é ir além dele, de suas limitações e localizações iniciais. Tematizar o corpo para o Para-si já seria, nesse sentido, estar para além dele como ponto de partida, pois o projeto inicial já está, de início, comprometido por um ato de transcender a situação do corpo, a facticidade específica daquela materialidade inicial: "Esse algo dado que sou sem ter-de-sê-lo -

projeta pensa no amanhã e no amanhã do amanhã; chega assim a esboçar o plano de sua existência inteira e a sacrificar cada detalhe, quer dizer, cada instante, à ordem do conjunto". 
salvo ao modo do não ser - não posso captar nem conhecer, pois é por toda parte retomado e transcendido, utilizado para meus projetos, assumido" (id., ib., p. 412-413). Ser uma facticidade é, primeiramente, ter nascido, ou seja, ter sido um passado a ser transcendido, uma nadificação primeira a ser efetuada como fuga do Em-si que se era sem ter de sê-lo (como corpo): "Nascimento, passado, contingência, necessidade de um ponto de vista, condição de fato de toda ação possível sobre o mundo: assim é o corpo, tal como é para mim” (id., ib., p. 413).

Tem-se, assim, a definição da primeira dimensão ontológica do corpo como revelação do modo como ele se dá para o Para-si como factidade (o absurdo e a gratuidade de ter nascido em determinado lugar, país, determinada família, possuir algumas características físicas e não outras, defeitos físicos ou mesmo doenças congênitas, pertencer a determinada cultura). O corpo é "condição permanente da possibilidade da minha consciência como consciência do mundo e como projeto transcendente rumo a meu futuro" (id., ib., p. 414), ao modo de ser ponto de partida, assim como "jamais podemos captar esta contingência como tal, enquanto nosso corpo é para nós, porque somos escolha, e ser é, para nós, escolhermos", ao modo de ser escolha (de acordo com um projeto) e ponto de vista - ou seja, apreender o corpo segundo um modo específico de transcender sua condição inicial rumo a um fim, o que determina "vê-lo" sob um aspecto, e não sobre todos, o que seria impossível para o homem.

Mesmo esta invalidez de que padeço, pelo próprio fato de vivê-la, eu a assumi, e a transcendo rumo a meus próprios projetos, constituo-a como o obstáculo necessário para meu ser; não posso ser enfermo sem me escolher inválido, ou seja, sem escolher a maneira como constituo minha invalidez (como "intolerável", "humilhante", "a ser dissimulada", "a ser revelada a todos", "objeto de orgulho", "justificativa para meus fracassos" etc.). Mas este corpo inapreensível é precisamente a necessidade de que haja uma escolha, ou seja, a necessidade de que eu não seja tudo ao mesmo tempo. Nesse sentido, minha finitude é condição de minha liberdade, pois não há liberdade sem escolha, e, assim como o corpo condiciona a consciência como pura consciência do mundo, minha finitude torna a consciência possível até mesmo em sua própria liberdade (id., ib., p. 414-415).

A segunda dimensão ontológica do corpo é a existência do corpo como para o outro. Nesse sentido, as explanações sobre o corpo aplicadas ao Para-si também servem para o outro, na medida em que este também é um Para-si. O que se tem aqui agora é a abordagem que serve para se compreender tanto o modo como o corpo do outro aparece para o Para-si como o corpo do Para-si aparece para o outro - Sartre diz que ambas as estruturas de aparecimento são as mesmas 
(id., ib., p. 426-427). Conforme já visto, o Para-si aparece ao outro como objeto; o olhar do outro capta o Para-si como um objeto, faz dele um ente de acordo com as coordenadas de seu mundo, mundo este que, além de ser desconhecido para o Para-si, ainda o aliena de seu próprio. O Parasi, nesse aspecto, percebe o outro, inicialmente, não como objeto, mas sim como sujeito ou outra consciência que o mira e o captura em forma de objetivação:

A aparição do corpo do outro, portanto, não é o encontro primeiro, mas, ao contrário, não passa de um episódio de minhas relações com o outro, e, mais especialmente, do que denominamos objetivação do outro; ou, se preferirmos, o outro existe para mim primeiro, e capto-o como corpo depois; o corpo do outro é para mim uma estrutura secundária (id., ib., p. 427).

Em relação ao mundo do Para-si, o outro é indicado inicialmente pelas coisas como um instrumento, ou seja, como objeto que vai representar-se para o Para-si de acordo com o seu projeto - como facilitador ou empecilho de seu fim: "Pelo simples fato de que não sou o outro, seu corpo aparece-me originariamente como ponto de vista sobre o qual posso adotar um ponto de vista, um instrumento que posso utilizar com outros instrumentos" (id., ib., 428). Mediante as coisas-utensílios pertencentes ao mundo do Para-si, o corpo do outro é revelado, ou melhor, o outro como corpo vem à tona e é integrado ao mundo do Para-si e indica o próprio corpo do Parasi. O corpo do outro é diferente do corpo do Para-si para ele mesmo. O corpo do outro é uma espécie de ferramenta, de instrumento, que o Para-si sabe não ser e que o utiliza. O outro como corpo apresenta-se ao Para-si "com certo coeficiente objetivo de utilidade e adversidade" (id., ib.).

O corpo do outro aparece como um outro centro de referência mediante os objetos pertencentes ao mundo do Para-si, pois os objetos referentes ao mundo do Para-si são ressignificados pelo outro, ganham uma outra resposta ou outro enquadramento (o outro pode revelar-se como concorrente, como ameaça ou mesmo como aquele que dá outro sentido para um objeto pertencente ao projeto original do Para-si): "Esse centro, por sua vez, aparece-me de um ponto de vista sem ponto de vista que é o meu, que é meu corpo ou minha contingência [...] o outro também é [...] uma facticidade que aparece a uma facticidade” (id., ib., 429).

O Para-si e o outro, ambos como corpo, revelam-se como um ser-aí com relação a um conjunto concreto de coisas-utensílios, em uma situação concreta, já é facticidade e contingência. As relações de objetivação, tanto do outro como do Para-si, demonstram ser dependentes das 
relações devedoras de suas contingências e facticidades. O Para-si percebe o outro a partir de um fundo de mundo que circunscreve o posicionamento que o outro ganha, a maneira como é objetivado pelo Para-si, de acordo com seus projetos, com os fins estabelecidos aos objetos, ou coisas-utensílios segundo seu mundo. O mesmo se dá ao Para-si sendo objetivado como corpo pelo outro. Sabe que é objeto em determinada relação do outro com seu mundo e as coisasutensílios correspondentes. O Para-si não tem acesso ao modo como é tematizado pelo outro, apenas sabe que o é porque vivencia essa experiência, seus sentidos permitem que perceba o olhar do outro sobre seu corpo, transformando-o em coisa, coagulando suas possibilidades.

Esse corpo do outro se revela, portanto, por duas características igualmente contingentes: está aqui e poderia estar em outro lugar, ou seja, as coisasutensílios poderiam dispor-se de outra maneira com relação a ele, indicá-lo de outro modo; a distância entre a cadeira e seu corpo poderia ser outra - seu corpo é assim, mas poderia ser diferente, ou seja, capto sua contingência original em forma de uma configuração objetiva e contingente. Mas, na verdade, essas duas características constituem apenas uma. A segunda não faz mais que presentificar e explicitar para mim a primeira. O corpo do outro é o puro fato da presença do outro em meu mundo como um ser-aí que se traduz por um ser-como-isto" (Sartre, 1997, p. 431).

Sartre enfatiza que jamais o corpo é captado fora da relação com os objetos de um mundo que o dotam de sentido. O corpo é "significante", em que "a significação nada mais é que um movimento coagulado de transcendência" (id., ib., p. 433). O corpo do outro é visto pelo Para-si a partir do destaque que ganha de acordo com os objetos contrastantes de seu mundo - o corpo para o outro representa um confronto entre mundos, entre um sistema diferente de objetos referidos ao seu próprio mundo: "O corpo é totalidade das relações significantes com o mundo [...] o corpo do outro, com efeito, aparece 'ao meu corpo'. Significa que há uma facticidade de meu ponto de vista sobre o outro" id., ib.). A segunda dimensão ontológica do corpo, no caso como corpo-paraoutro, é o reconhecimento da utilização e do conhecimento do corpo do Para-si pelo outro, o que pressupõe uma relação mútua, já que o Para-si também utiliza e, de certa forma, conhece o outro, ainda que esse conhecimento seja devedor dos "arredores" de seu mundo, não seja de fato um conhecimento pleno do corpo do outro, pois o outro está sempre para além do processo de objetividade efetuado pelo Para-si: 
O corpo - seja como organismo, caráter ou ferramente - jamais me aparece sem arredores e deve ser determinado a partir desses arredores. $\mathrm{O}$ corpo do outro não deve ser confundido com sua objetividade. A objetividade do outro é sua transcendência como transcendida. O corpo é a facticidade desta transcendência. Mas corporeidade e objetividade do outro são rigorosamente inseparáveis (id., ib., p. 440-441).

Com as duas exposições, até então, do que seriam as dimensões ontológicas do corpo, tem-se que: o Para-si existe seu próprio corpo (id., ib., p. 416), sendo esta a primeira dimensão de ser; o corpo do Para-si é utilizado e conhecido pelo outro, sendo esta a segunda dimensão. Mas enquanto o Para-si é Para-outro, o outro se mostra como sujeito que faz do Para-si objeto. O Parasi, pelo olhar do outro, percebe-se como objeto de uma consciência que não a sua própria - essa é para Sartre a relação fundamental do Para-si com o outro (id., ib., p. 441). O Para-si, portanto, existe para si mesmo como aquilo que é conhecido pelo outro, ele existe como sendo conhecido pelo outro (de acordo com sua facticidade): "Existo para mim como conhecido pelo outro a título de corpo. Esta, a terceira dimensão ontológica de meu corpo" (id., ib.).

O olhar do outro produz a experiência para o Para-si de ser revelado como um Em-si, um ser-objeto, cuja transcendência é transcendida pelo outro. Esse objeto, esse ser, que o outro revela ao Para-si é incognoscível, pertence aos domínios do outro, mas, frisa Sartre, nem por isso o Para-si é menos responsável por essa dimensão de si que vem à tona. Ainda que não conheça por completo essa espécie de "eu” revelada pelo outro, o Para-si capta certas estruturas dele, o concebe de alguma forma, algo chega a ele: "Sinto-me alcançado pelo outro em minha existência de fato; é por meu ser-aí-Para-outro que sou responsável. Este ser-aí é precisamente o corpo [...] e, na medida que sou consciente de existir para o outro, capto minha própria facticidade" (id., ib.). O encontro com o outro, produz, segundo Sartre, um "choque", que revela ao Para-si a perspectiva de ter seu corpo exteriorizado pelo outro como um Em-si.

Como essa relação com o outro sempre se dá, é irremediável, o Para-si se sabe constantemente objetivado, é uma dimensão permanente de sua facticidade. Sartre diz que o Parasi existe sua contingência transcendendo rumo a seus possíveis, mas, no entanto, sua contingência lhe escapa em tua totalidade, na medida em que o corpo do Para-si “está-aí" não apenas como ponto de vista que o Para-si é, mas também como ponto de vista sobre o qual são adotados outros pontos de vista que Para-si não tem controle ou conhecimento - o corpo escapa dos domínios do 
Para-si por todos os lados: "Uma vez que minha facticidade é pura contingência e revela-se a mim não-teticamente como necessidade de fato, o ser-Para-outro desta facticidade vem multiplicar a contingência desta facticidade: ela se perde e me foge em um infinito de contingência que me escapa" (id., ib., p. 442). Essa perspectiva de ser "atacado", acossado por diferentes "pontos de vista", acaba por relativizar a facticidade do Para-si, pois outras facticidades vêm à tona a partir da percepção que o Para-si tem de que seu corpo é tematizado, julgado e enquadrado sob diversos enfoques e circunstâncias:

Assim, a relatividade de meus sentidos, que não posso pensar abstratamente sem destruir meu mundo, é ao mesmo tempo perpetuamente presentificada a mim pela existência do outro; mas é uma pura e inapreensível presentificação [...] Meu corpo, enquanto alienado, escapa-me rumo a um ser-ferramenta-entreferramentas, rumo a um ser-órgão-sensível-captado-por-órgãos-sensíveis, e isso com uma destruição alienadora e um desmoronamento concreto de meu mundo, que escoa rumo ao outro e que o outro irá retomar em seu mundo (id., ib.).

O outro cumpre uma função que é vedada ao Para-si, qual seja, produzi-lo como Em-si, transformá-lo em objeto, objeto este que permite ao Para-si "se ver como é". Aqui entra em cena um importante elemento de mediação entre o Para-si e o outro: a linguagem (id., ib., p. 394). A linguagem é o elemento que permite a revelação do modo como o Para-si é visto pelo outro, ela fornece um "saber" que impregna o modo com o qual o Para-si tematiza o outro. O Para-si só tem o mínimo acesso a seu corpo mediante os conceitos que o outro formulou sobre ele, em uma tentativa de adotar a perspectiva que o outro tem em relação a ele: "Esta aparição do corpo não nos entrega o corpo enquanto age e percebe, mas sim enquanto é agido e percebido [...] a natureza de nosso corpo para nós nos escapa inteiramente, na medida em que podemos adotar sobre ele o ponto de vista do outro" (id., ib., p. 449). Sartre fala sobre uma "assimilação analógica" que a linguagem permite a partir da aparição do corpo do Para-si mediante a posição do outro:

O corpo-Para-outro é o corpo-para-nós, porém inapreensível e alienado. Parece então que o outro cumpre por nós uma função para a qual somos incapazes e que, no entanto, cabe-nos executar: ver-nos como somos. A linguagem, ao nos revelar - no vazio - as principais estruturas de nosso corpo-Para-outro (enquanto o corpo existido é inefável), incita-nos a descarregar inteiramente nossa pretendida missão em cima do outro. Resignamo-nos a nos ver pelos olhos do outro; significa que tentamos conhecer o nosso ser pelas revelações da linguagem. Aparece assim todo um sistema de correspondências verbais, pelo 
qual fazemos com que nosso corpo seja designado tal como é para o outro, utilizando essas designações para nomear nosso corpo tal como é para nós. É nesse nível que se produz a assimilação analógica entre o corpo do outro e o meu (id., ib., p. 444).

A objetividade do corpo do Para-si não é objeto para ele mesmo, ela já é experimentada como fuga desse corpo que o Para-si existe, na medida em que o Para-si existe já como transcendência originária desse Em-si primordial que é o corpo - o corpo como ponto de partida a ser transcendido rumo aos fins estabelecidos pelo Para-si. Qualquer estrutura que possa ser minimamente cognoscível do ser do Para-si a ele mesmo, ou seu corpo, ocorre por intermédio da alienação efetuada pelo outro ao travesti-lo de objeto segundo a realidade do outro, que, no máximo, compartilha de coisas-utensílios que podem ser, analogicamente, aproximados do mundo do Para-si por intermédio da linguagem.

Meu visar impregna-se do saber que a linguagem me forneceu, ou seja, utilizo conceitos instrumentais que me chegam do Outro e que de modo algum eu teria podido formar sozinho ou pensar por mim mesmo em dirigir ao meu corpo. É por meio dos conceitos do Outro que conheço meu corpo. Mas segue-se daí que na própria reflexão adoto o ponto de vista do Outro sobre meu corpo; tento captá-lo como se eu fosse o Outro com relação a ele (id., ib., p. 445).

O projeto fenomenológico de Sartre, ao interpretar a consciência como desprovida de ser, como busca de ser na forma de intencionalidade e transcendência, acabou por revelar duas formas, ou instâncias de ser: o Para-si (a própria consciência) e o Em-si (o mundo, a realidade, a externalidade objetiva). Essa cisão, que se revela na filosofia sartriana como irreconciliável, apresenta a perspectiva na qual a tentativa de ser da consciência - o Para-si tentanto se tornar um Em-si (mas mantendo sua autonomia, sua liberdade de Para-si) - demonstra-se como impossível de ser consumada, já que essas duas regiões do ser são perpetuamente separadas pelo nada, nada este como estrutura originária e fundamental da existência humana. O homem tenta, mas não pode ser, é impossibilitado de ser, pois sua consciência escorre por todos os lados, não se deixa coagular.

A empreitada filosófica que começa em uma fenomenologia da concretude humana acaba por desembocar em uma ontologia que apresenta, incontornavelmente, o fracasso de ser para o homem. Mas não só isso. Como a filosofia satriana bem salienta, o homem já está, mesmo 
fenomenologicamente, comprometido com a ação, originariamente, pois "ver" já implica ver de determinada maneira, salientar, recortar, enquadrar segundo um projeto de ser, projeto que se materializa nas escolhas que a realidade humana faz. O homem, conforme enfatiza Sartre (2004, p. 21), é "o ser que não pode sequer ver uma situação sem mudá-la, pois o seu olhar imobiliza, destrói, ou esculpe [...] transforma o objeto em si mesmo". Com isso, o homem faz vir ao mundo o "valor", que confere sentido a suas ações (segundo uma determinada perspectiva, um mundo). Só por isso, a ontologia fenomenológica sartriana já levantaria problemas de cunho ético, pois se haveria de investigar o modo de confecção desses valores e suas correspondentes consequências. Mas há outra questão de implicação ética: a revelação do outro para a consciência.

Nem todo ser objetivado para a consciência será puramente, meramente, um Em-si na forma das coisas, será de um simples objeto. A consciência, ao mesmo tempo que observa e tematiza a realidade à sua volta, dotando-a de sentido e fazendo-a ser, também se percebe alvo de outro olhar, de uma outra consciência que também a classifica e julga. Na verdade, Sartre diz que, antes de olhar, a consciência é olhada, e, a partir daí, seu voltar-se para o outro já é uma reação ao processo de objetivação que sofre impreterivelmente.

O homem só vem a ser - ser é ser objetivado - por intermédio do outro. Mas essa possibilidade de ser não é a alternativa que a consciência busca para si mesma, pois não permite que o Para-si seja um Em-si-Para-si, ou seja, que adquira identidade, essência, mas que continue a ser liberdade, a ser senhora de seu destino. Ser ser-Para-si-Para-outro implica justamente o contrário, não ter controle sobre sua situação, estar à mercê da liberdade do outro, que é sempre imprevisível. No entanto, essa relação conflituosa ${ }^{3}$ de liberdades não quer dizer que o outro signifique para o Para-si um elemento que permita a este se dizer por algum momento "não livre". O corpo é a facticidade radical da realidade humana, e é o que coloca em contato um Parasi com outro Para-si, o que faz do homem um ser-Para-si-Para-outro como ser que tem de vivenciar sua facticidade ao modo do velamento e da ameaça constante do outro; mas, simultaneamente, é o ser que transcende sua situação, confere valor a esse transcender de acordo com seus fins (devedores e remetentes ao seu projeto original de ser um Em-si-Para-si). Como bem define Cox (2010, p. 75):

\footnotetext{
${ }^{3}$ Sartre entende que o sentido originário do ser-Para-outro é o conflito (Sartre, 1997, p. 454), conforme sintetiza Franklin Leopoldo e Silva, fazendo alusão ao célebre trecho de Hui clos ("o inferno são os outros"): "O ser-Para-
} 
O corpo representa a situação imediata e inescapável do para-si que o para-si perpetuamente supera em direção às situações futuras. $\mathrm{O}$ corpo é o contingente dado que o para-si transcende perpetuamente. Entretanto, o para-si é perpetuamente recapturado pelo corpo, pois o corpo é a possibilidade, a base, da transcendência do para-si. Em outras palavras, o para-si é aquele que supera perpetuamente o corpo sem nunca ser capaz de considerá-lo, finalmente e completamente, superado.

Embora o Para-si não tenha conhecimento ou controle sobre a liberdade do outro, e o modo como o outro o tematiza e o objetiva, a forma de vivenciar essa significação que o outro lhe confere acompanhará sua maneira de experimentar essas "limitações" à liberdade de acordo com o seu projeto original, que confere sentido e propicia suas escolhas. Os limites à liberdade do Para-si são os que ele impõe a si mesmo, mediante o exercer de sua liberdade como ação, na sua busca e tentativa de ser. Aqui, a facticidade toca outra questão cara ao pensamento sartriano que reforça, novamente, o aspecto ético de suas reflexões: a responsabilidade.

A consequência essencial de nossas observações anteriores é a de que o homem, estando condenado a ser livre, carrega nos ombros o peso do mundo inteiro: é responsável pelo mundo e por si mesmo enquanto maneira de ser. Tomamos a palavra 'responsabilidade' em seu sentido corriqueiro de 'consciência (de) ser o autor incontestável de um acontecimento ou de um objeto'. Nesse sentido, a responsabilidade do Para-si é opressiva, já que o Para-si é aquele pelo qual se faz com que haja um mundo, e uma vez que também é aquele que se faz ser, qualquer que seja a situação em que se encontre, com seu coeficiente de adversidade próprio, ainda que insuportável; o Para-si deve assumi-la com a consciência orgulhosa de ser o seu autor, pois os piores incovenientes ou as piores ameaças que prometem atingir minha pessoa só adquirem sentido pelo meu projeto; e elas aparecem sobre o fundo de comprometimento que eu sou. Portanto, é insensato pensar em queixar-se, pois nada alheio determinou aquilo que sentimos, vivemos ou somos. Por outro lado, tal responsabilidade absoluta não é resignação: é simples reivindicação lógica das consequências de nossa liberdade. O que acontece comigo, acontece por mim, e eu não poderia me deixar afetar por isso, nem me revoltar, nem me resignar (Sartre, 1997, p.678).

outro é estruturalmente conflituoso. Os antagonismos concretos, de qualquer alcance, derivam desse traço ontológico, que torna infernal as relações humanas" (Leopoldo e Silva, 2004, p. 190). 


\section{REFERENNCIAS}

COX, Gary. Compreender Sartre. 2 ed. Petrópolis: Vozes, 2010.

DONIZETTI DA SILVA, Luciano. A filosofia de Sartre: entre a liberdade e a história. São Carlos: Claraluz, 2010.

JOLIVET, Régis. Sartre ou a teologia do absurdo. São Paulo: Herder, 1968.

LEOPOLDO \& SILVA, Franklin. Ética e literatura em Sartre: ensaios introdutórios. São Paulo: Ed. Unesp, 2004.

MORAVIA, Sergio. Sartre. Lisboa: Edições 70, 1985.

SARTRE, Jean-Paul. Situações I: crítica literária. São Paulo: Cosac \& Naify, 2005. - Que é a literatura? São Paulo: Ática, 2004. O ser e o nada: ensaio de ontologia fenomenológica. Petrópolis: Vozes, 1997. 